\title{
The Development of Status Distinctions under Conditions of Inequity ${ }^{1}$
}

\author{
Eugene Burnstein and Robert J. Wolosin \\ The University of Michigan
}

\begin{abstract}
To distribute a status, such as task responsibility, so as to maximize the expected value of its outcome, a group may be forced to violate standards of equity and thereby do harm to affective relations among members. The circumstances under which this is likely were specified as follows: If a rational distribution of responsibility requires marked discrepancies in status, inequities occur (1) as the individual differences in task proficiency decrease, and (2) as the status becomes an increasingly significant reward or cost. Dyads performed a group reaction-time task in which they decided how much cach mcmber's performanee would count in determining the joint outcome. Initially each performer had equal responsibility for the joint outcome. The rational solution was to permit the superior performer to assume complete responsibility. Under conditions of maximal inequity there was a tendency to avoid such a distribution, to wit, the rate at which the inferior performer was divested of responsibility was considerably slower than under conditions of minimal inequity. Furthermore, the inferior performer seemed to compensate for his humiliation by taking the lead in advocating a rational reorganization of the status hierarchy, while the superior performer seemed to make amends to his partner by allowing him to control decisions to reorganize and by evidencing a personal preference for a status distribution that was relatively lenient on the latter, one that would not maximize the expected value of their outcome.
\end{abstract}

A group will usually profit by permitting a superior performer to assume greater responsibility than an inferior performer for their joint outcome. Indeed, such arrangements have been observed to be readily instituted in response to individual differences on a simple group reaction-time task even when rather large variations in responsibility are involved (Burnstein and Zajonc, 1965a, 1965b). That this should be so may at first appcar obvious. Not only do we think it normal for responsibility to be associated with proficiency, but we also expect that were members in the least concerned with the value of their outcome they

${ }^{I}$ This research was supported by a grant from the National Science Foundation (GS-750). 
would in short order recognize this as the rational solution to the problem of individual differences in performance. It would be quickly seen that responsibility must be distributed this way in order for the group to maximize the expected value of its outcome. Hence, little difficulty should be anticipated when it is necessary to assign unequal responsibility to members. At the same time, ordinary experience tells us otherwise. Status distinctions along a value-laden dimension, such as responsibility, are rarely distributed optimally without some difficulty. In the present paper we will examine one important constraint on "optimizing": that is, a status hierarchy that assigns greater weight to the performance of the more successful than to that of the less successful will in certain circumstances grossly violate common standards of equity.

Roughly, the concept of equity has been formulated in terms of two ratios: (a) the investment a person makes by virtue of his performance, compared to the profit he receives for this performance; and (b) the investment made by relevant others, compared to the profit they receive (Homans, 1961; Adams, 1965). Investments may be reflected simply by the time and energy the person devotes to the activity. Profits depend on the rewards received minus the costs incurred. Note that rewards refer not only to material benefits but also to the respect and affection given by others as a consequence of engaging in the activity. Similarly, costs refer not only to matcrial losses (due either directly to the present activity or to foregoing attractive alternative activities), but also to the disrespect or disaffection shown by others. Inequity, by definition, increases as the ratios depart from equality, and this will occur if there is a change in the individual's investment or profit (rewards and costs) relative to that of others.

Inequity has been assumed to have noxious effects. Those who benefit, i.e., those whose rewards increase or whose costs decrease relative to others, are said to experience embarrassment or guilt; those injured, i.e., those whose rewards decrease or whose costs increase relative to others, are said to experience humiliation or anger. As a result, the individual desires to maintain or restore equity and will act to satisfy this desire. For example, in work by Adams (1965), individuals who were overrewarded in terms of their qualifications for a job tended to increase their output if they were to be paid by the hour (an increase in their investment), and to decrease their output by lavishing extra care on their work if they were to be paid by the piece (a decrease in their profits). Burnstein and Zajone (1965a) found a decline in effort, as measured by changes in reaction time, when co-workers decided to reduce a member's responsibility for the group outcome, and an increase in effort after a decision to enhance his responsibility-effects readily interpreted as changes in investment that restore equity. 
Our general proposition is that an optimal distribution of responsibility that creates an inequity in status will be more difficult to arrive at than one that does not. In order to more elearly specify the circumstanecs in which this effect occurs, to wit, the conditions under which equity is violated, let us consider the following example: Two individuals are engaged in a group task that extends over a long scries of trials. After each trial the group receives a payoff in which each member shares equally. The value of the joint outcome depends on which performer succeds and how much his performance counts. Say, the maximum value of the joint outcome for any trial is $\$ .20$ and the two individuals can decide the extent to which each of their performances determines the outcome. Thus, they may share responsibility for the outcome equally so that each performer adds $\$ .10$ to the outcome if he succeeds and nothing if he fails; in this case, when both succeed they win the maximum, $\$ .20$, and when either one fails and the other succeeds they obtain one-half of the maximum, $\$ .10$. Of course, if both fail, they receive nothing for that trial. Suppose, however, they decide that one of them should have the greater responsibility, say, that his performance should count for three-quarters of the joint outcome (\$.15) and that the other's performance should count for one-quarter (\$.05). Now when both suceed, they still obtain the maximum of $\$ .20$. But, if only one succeeds, the joint outcome is cither three-quarters of the maximum (\$.15) or one-quarter of the maximum (\$.05), depending on which member is successful. If each member is equally likely to succeed it makes no difference, in terms of the expected value of their joint outcome, how responsibility is allocated. On the other hand, when one member is more likely to succeed than the other, it makes a considerable difference. In the latter case, the value of their joint outcome can be maximized if and only if the more successful performer is given greater weight. It is important to note that in this hypothetical situation, which is quite similar to the one to be described in the following experiment, the weights given to performers are combined additively, when they succeed, to determine the value of the group outcome. Given this rule for combining individual performances, it can be shown that when individual differences in the likelihood of success exist, regardless of the size of the difference, the rational solution is to assign total responsibility to the more successful performer. Only then will the group be able to achieve outcomes of maximal value. Table 1 demonstrates that having each performance count equally or having one count more than the other has no effect on the outcome if members are equally successful. But when one member is more successful than the other, they will obtain their most profitable joint outeome only if the former is given complete responsibility-regardless of whether he is much or just slightly better.

To pursue our analysis, let us make two assumptions. First, a group de- 
TABLL 1

The Relationship between the Expecten Valee of a Joint Oetcome and the Probability of Success(Ps) of Two Performers (A ani) B) when They Are Assigned Equal or Differext Weights

\begin{tabular}{|c|c|c|c|c|c|c|c|c|}
\hline & $P_{S}(1)$ & & eight $(A$ & & $P_{s}(B)$ & & $\operatorname{eight}(B)$ & $\begin{array}{c}\text { Expected } \\
\text { value }\end{array}$ \\
\hline \multirow[t]{3}{*}{ No difference in Ps } & 7 & $x$ & 10 & + & .7 & $x$ & 10 & 14 \\
\hline & .7 & $x$ & 15 & + & .7 & $x$ & 5 & 14 \\
\hline & .7 & $x$ & 20 & + & .7 & $x$ & 0 & 14 \\
\hline \multirow[t]{3}{*}{ Small difference in Ps } & .8 & $x$ & 10 & + & 6 & $x$ & 11) & 14 \\
\hline & s & $x$ & 15 & + & 6 & $x$ & 5 & 15 \\
\hline & .8 & $x$ & 20 & + & 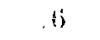 & 冫 & 0 & 16 \\
\hline \multirow[t]{3}{*}{ Large difference in Ps } & .9 & $x$ & 10 & + &. $\bar{j}$ & $x$ & 10 & 14 \\
\hline & .9 & $x$ & 15 & + & .5 & $x$ & 5 & 16 \\
\hline & .9 & $x$ & 20 & + & .5 & x & 0 & 1.9 \\
\hline
\end{tabular}

cision to assign one member more responsibility than the other is, among other things, public recognition of the relative respect in which he is held as a performer. It legitimizes his superiority. Second, the effort and skill a member commits to the task-his investment-is demonstrated by the frequency with which he performs successfully. Now the optimal or rational distribution of responsibility was shown to be one in which the more successful member's performance completely determines the joint outcome. Since responsibility is assumed to be a reward, it follows that such a distribution will be more inequitable, and therefore more difficult to achieve, when individual differences in performance are small than when they are large. When differences are large the more successful performer, by virtue of his extraordinary effort and skill, has made a much larger investment in the activity than has his co-worker; thus, large differences in reward are justified and there is no appreciable violation of equity in the former's receiving the overwhelming share of responsibility for the group outcome. When, however, differences in performance are small, the superior performer has made an only slightly greater investment than his partner; under these conditions very large differences in reward are unjustified, and the assignment of complete responsibility to the superior performer would create an appreciable inequity.

Status is here defined in terms of the responsibility associated with a position. If a person's position is to serve as a source of guilt or of anger, it is critical that assigned responsibility be interpreted as the group's evaluation of the individual performer, that it be seen in large part as reflecting the esteem in which his performance is held. Were it not possible to interpret status as an evaluation of the individual performer, or were such evaluations inconsequential to the performer, then gains or 
losses in responsibility would have no significance as rewards or costs. This implies that when status distinctions in the form of differential responsibility are instituted but do not reflect an evaluation of consequence to the performer, equity is not likely to be violated, even if the difference in responsibility is grossly disproportional to the difference in individual performance. In the following experiment, in addition to the case in which assigned responsibility reflects an important evaluation, we will examine two conditions in which decisions to increase the responsibility of the more successful pcrformer and to decrease that of the less successful performer should have little significance as rewards or costs: (1) where individual success or failure is not determined by effort or skill but by some external agent such as the experimenter or chance; and (2) where task performance is perceived to reflect a totally unimportant proficiency.

\section{METHOD}

\section{Subjects}

The subjects were 72 male volunteers recruited from the University of Michigan paid subject pool. They received $\$ 1.25$ per hour for participating in the experiment.

\section{Apparatus}

The Group Reaction-Time Apparatus that was used in the present study is described in greater detail elsewhere (Zajonc, 1965). We shall therefore limit ourselves to its main operational features. The apparatus consists of individual panels and a control console operated by the experimenter. Each panel contains stimulus lights, failure signals, and reaction switches. In the present experiment simple reaction times were observed for each member of 36 two-man groups. In all conditions the onset of a white light on the subjects' panels constituted the critical stimulus. An individual was required to push a toggle switch forward as quickly as he could after its onset. A reaction was considered supposedly "successful" if, and only if, it occurred within a certain specified interval after stimulus onset. Reactions that had longer latencies were defined for the subjects as "failures," and were signaled by red "failure" lights on the subjects' panels. Actually, the appearance of the failure signal was controlled by the experimenter independently of the subjects' reactions and according to a fixed schedule described below. A distance of only 2 or 3 feet separated each pair of subjects, and they were told to observe each other's panel as well as their own for the appearance of the failure light.

\section{Procedure}

As soon as possible after coming into the laboratory the two subjects were introduced to one another and told that they would bc working as a group after they mastered their individual tasks. Individual practice at the reaction-time task was given in a series of 20 "preliminary" trials. Subjects were instructed to push their reaction keys as quickly as they could upon the onset of the stimulus lights on their panels. A ready signal (buzzer) was turned on by the experimenter. Immediately upon termination of the ready signal, the stimulus light went on. The subject's re- 
action turned off his own stimulus light. Trials within a given block of five wre separated by a 10 -secend interval, and trial blocks wore sriarated by 30 -second intervals. During the "preliminary" or practice interval, the rod "failure" light was not used.

After the practice trials, the subjects were asked to rank each other in terms of speed of reaction. This had to be done on the basis of their observations alone, without any lnowledge of the actual timos. It served to orient them to individual differences in performance that wore to be exploited later. After having ranked each other, the subjects were told that they were to work together at a simple task in competition with other grours. The task was described as follows:

"You are taking part in a study of group performance. You are one of the 50 groups that will participate in this study. Each has the opportunity to earn a certain number of points. At the end of the study, the members of the group with the most points will receive $\$ 10.00$ each in addition to the pay you will be given today. If there is a tie among two or more groups for the most points, each member of the winning groups will receive $\$ 5.00$, regardless of the number of tied groups.

"How are these points to be earned? I would like you to notice the red light in the lowermost lefthand corner. This light, marked " $F$," will also go on, but only when you fail to press quickly enough to beat a pre-set interval of time. Thus, the red light marked " $\mathrm{F}$ " is the failure light.

"A group will receive points when at least one member, either of you, presses fast enough to prevent the failure light from coming on. If either member heats the failure light, he contributes his points to the group total. If both members beat the failure light, the sum of both members' points is added to the group total. If neither member beats the failure light, the group gets nothing for that trial. The number of points a member can contribute is indicated by the number of poker chips he has-here are $\mathbf{1 0}$ chips for cach of you."

Examples were then given of how the group's total would depend on whether rach member had the same or a different number of chips, and, if each had a differnt number, on who had the most and who the least. For instance,

". . . if one member has 15 chips, and the other member has 5 chips, then if only" the first member beats the failure light, the group gets 15 points; if only the second member beats the failure light, the group gets 5 points; and if both mombers beat the failure light, the group gets 20 points. If neither member beats the failure light, the group gets nothing. Is this clear? All groups participating in the study hilw the same point system and thus the same chance to carn points."

At this point, the task-importance induetion was given to the subjects .Groups wrere assigned randomly to one of threc importance conditions. The induetions wore as follows:

Induction 1: Important Performance. (IP). "Let me now briefly give you some background on what you will be doing. Each of you will perform a reaction-time task. This is one of the oldest and still one of the most widely used tasks in studying individual differences in sensory-motor capacity. Originally, in the 1870 's, psychologists were interested in the efficiency with which a person responded to various classes of stimuli. For cxample, would visual signals produce a more raprid reaction than auditory signals? From such work much was learned of how the central nervous system processes information transmitted by the different scnses. Early research established that individual differences in reaction time reflected differences in sensory-motor functioning in the central norrous system. As a result researchers began to wonder whether people with slow reaction times worn different in other respects from those with quick reaction times. 
"During and since the second World War', using much the same task that you will perform here, these experimenters found that, indecd, intellectual functioning and personality adjustments were significantly related to reaction-time performance. For example, individuals with fast reactions tended to be more fexible and adaptive in adjusting to environmental changes, more creative in solving problems, generally more intclligent, better able to endure strong stresses, and psychologically better adjusted. Those with slow reaction times tend to be more rigrid and maladaptive in dealing with a changing environment, relatively uncreative in problemsolving, less intelligent, unable to endure strong stresses, and rather maladjusted. Morcover, reaction-time differences are quite consistent. If one person is faster than another initially, he remains faster.

"The task that you will be engaged in, thus, has played a long and productive part in research on the individual personality and its capacitics. Wc are using it here in a slightly different way, as a measure of your performance in a simple game when you are operating as a team playing against others."

Induction 2: Unimportant Performance (UP). "Let me orient you to what you will be doing. Each of you will perform a simple reaction-time task. This is a common kind of response in psychological experiments because it is very convenient to work with. It is a very simple thing to do, merely pressing a button or closing a switch. Anyone can do it without training and it is easy to observe and measure. Also, reaction time is influenced mainly by the situation. It is unrelated to intellectual or personality traits. Although individuals differ in reaction time, this difference does not seem to have any significance in terms of the porson's croativity, intelligence, or psycholngical adjustment. There are just as many intelligent, creative, well-adjusted people who have long reaction times as have short reaction times. Moreover, although one person in a given situation will respond somewhat more quickly or somewhat more slowly than another person, and this difference is consistent within the situation, that is, if he is initially slower, he remains slower and if he is faster, he remains faster in that situation, this difference in response speed very often is reversed in another, different situation. Rcaction time is merely an uncomplicatcd, convenicnt, and easily measured response which reflects the situation. We are using it here as a performance device in a simple game to obscrve how you as a team play against others."

Induetion 3: Chance (C). "You may be interested to know that each momber of the group has a different time to beat. That is, the failure interval will he different for each member of the group. The times have already becn assigned at random before the experiment began. One of you will have a relatively long or "eary" tim to beat, and the other will have a somewhat shorter, "hard" lime to beat. Therefore, whether you suceed or fail has little to do with your own ability, and depends on which interval you happened to be assigned to. Is this elcar?"

One trial block of five trials was given so that the subjects might become accustomed to working against the failure signal. On this block, the fixed schodule of failures for each subject was initiated. For one member (chosen at raniom) the schedule allowed him ostensible sucess $50 \%$ of the time-that is, out of 10 trials (two blocks) he succerded half the time and failed half the time. The other member had one of thrce failure schedules: $50 \%$ success, $70 \%$ sucess, or $90 \%$ success. The schedules were drawn from a random-number table so that in every two trial blocks, the proportion of failures was constant. There were, thus, three levels of performance difference: a relatively large difference of 40\% (50-90), a relatively small difference of $20 \%(50-70)$, and no difference $(50-50)$. The subjects were then reminded that they each had ten poker chips. These poker chips represented the number of points 
that each could contribute to the group total if he were successful on a particular trial. They could redistribute these chips in any way they wished after each trial block. This was accomplished by means of "ballot sheets" on which they not only kept track of each member's successes and failures and the number of points won by the group, but also voted at the end of each trial block whether or not to change the way the poker chips were distributed. If a member voted "yes," to change the distribution, he indicated the number of points he and his partner should be given. If a member voted "no," he recorded the way chips were distributed at the time of the vote. Only when both members voted to change the distribution of chips were they allowed to discuss the allocation and change it. In fact, when both indicated a preference for change, they were obliged to make a change of at least one chip. The mechanics of this were as follows: After each trial block, ballot sheets were filled out by each subject. After they voted, they placed the ballot sheets face down in the center of the table. The experimenter then scrutinized each ballot sheet, and announced whether or not there was unanimous preference for change. If there was unanimous preference for change, the subjects could discuss reallocation and the experimenter would make the agreed-upon change by taking chips from one member and putting them in front of the other member. If there was no unanimous preference for change, the experimenter returned the ballot sheets and started the next trial block.

The experimental session was terminated when (1) no unanimous "yes" vote occurred within 15 blocks; (2) no second unanimous "yes" vote occurred within four blocks after the first reallocation; (3) no third unanimous "yes" vote occurred within three blocks of the second reallocation; (4) no other unanimous "yes" vote occurred within two blocks of the third or any later change. No group met the criteria for termination before completing at least six trial blocks. All instructions were presented via tape-recorder. Subjects did not know of the contingency between their unanimous preferences for change and the number of trial blocks. The ballot sheet contained enough space for a maximum of 15 blocks. If a subject asked the experimenter how many blocks the group would have, the experimenter simply said that he could not tell them. Throughout the session the experimenter remained outside of the experimental room, going in only (1) at the very beginning to introduce and seat the subjects, (2) at the end of the tape-recorded instructions to make sure the subjects understood them, (3) between each trial block to read and announce the results of the vote and to supervise any redistribution of chips, and (4) after

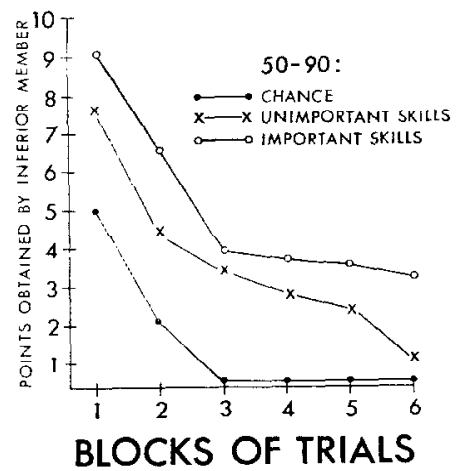

Fia. 1. Mean number of points given to the inferior performer on the basis of a group decision when difference in performance between members is large. 


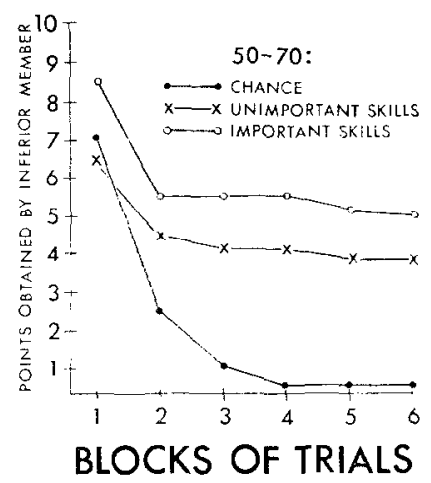

FIG. 2. Mean number of points given to the inferior on the basis of a group decision when difference in performance between members is small.

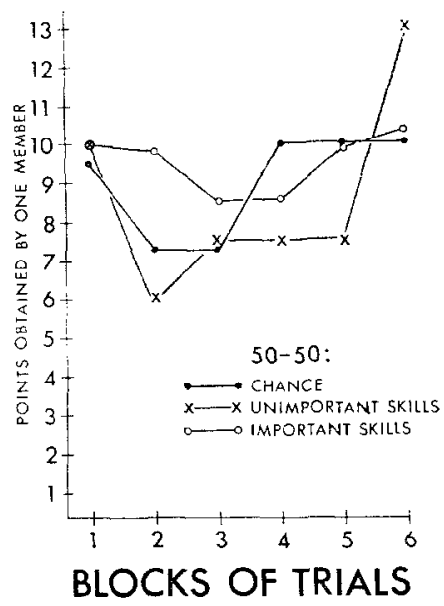

Fig. 3. Mean number of points given to a performer on the basis of a group decision when there is no difference in performance between members.

the experimental session to give a final debriefing. Subjects received complete feedback regarding the nature of the experiment. Any questions were answered at some length, and the subjects promised not to discuss the experiment for the next several weeks.

\section{RESULTS}

When the superior performer gains all 20 points and the inferior performer possesses none, the group has distributed responsibility so as to maximize the value of its outcome. The ease with which this is achieved may be seen in the rate with which the inferior member loses points over trial blocks. This is shown in Figs. 1, 2, and 3 for the 50-90, 50-70, and 50-50 conditions, respectively. It is apparent that when members are 
equally likely to succeed (50-50) there is no systematic change in the distribution of points over blocks. Hence, in the following analyses the $50-50$ condition is omitted unless otherwise stated. Analysis of variance of the 50-90 and 50-70 conditions indicates significant main effects for trials $(F=3.83,5$ and $90 d f, p<.01$ ) and for importance of the performance $(F=6.49,2$ and $18 d f, p<.01)$. The Pcrformance Difference $\times$ Trials interaction was also significant $(F=2.81,5$ and $90 \mathrm{df}, p<.03)$. The mean points possessed by the inferior performers in the 50-70 conditions on blocks 1 and 2 combined were compared with those in the 50-90 conditions by a $t$ test; the difference was not reliable. The same comparison for the means on blocks 3 and 4 combined, as well as for the means on blocks 5 and 6 combined, indicated reliable differences at the .03 and .05 levels, respectively. In both the 50-70 and 50-90 Chance conditions, groups rapidly achieve an optimal distribution of points, and by the fourth block nearly all of them have completely divested the inferior performer of control over the outcome. This process is somewhat slower when performance reflects an important skill and when the difference between members is relatively small. Thus, the inferior performer loses points most slowly over trial blocks in the IP/50-70 condition and, excluding the Chance groups, most rapidly in the UP/50-90 condition.

After every block of five trials each member indicated whether he wished to change the distribution of points and how. The ballots were shown to the experimenter, and if both expressed a preference for change, they engaged in a brief discussion to decide on a specific redistribution. It was stressed by the experimenter that their written prefercnce in no way committed them to advocating a particular assignment of points in the discussion. In each group the superior and inferior members' own preferences were compared to the obtained distribution of points, i.e., the distribution agreed to in the group decision, in terms of difference scores (points obtained minus points preferred). The means of these difference scores in respect to the inferior performer over six blocks are given in Table 2 . They denote the number of points the superior member judges his partner should have and the number of points the inferior member feels he himself should have, each of these values being subtracted from the actual number of points that they jointly decide to give to the latter for the next block of trials. A positive value indicates that the member preferred fewer points for the inferior performer than the latter actually received as a result of the decision; a negative value, that the member preferred more points for the inferior performer. The algebraic sums of the differences over the five trial blocks were subject to analysis of variance. A constant of 15 was added to each score to remove minus values. A significant main effect for performance importanec was 


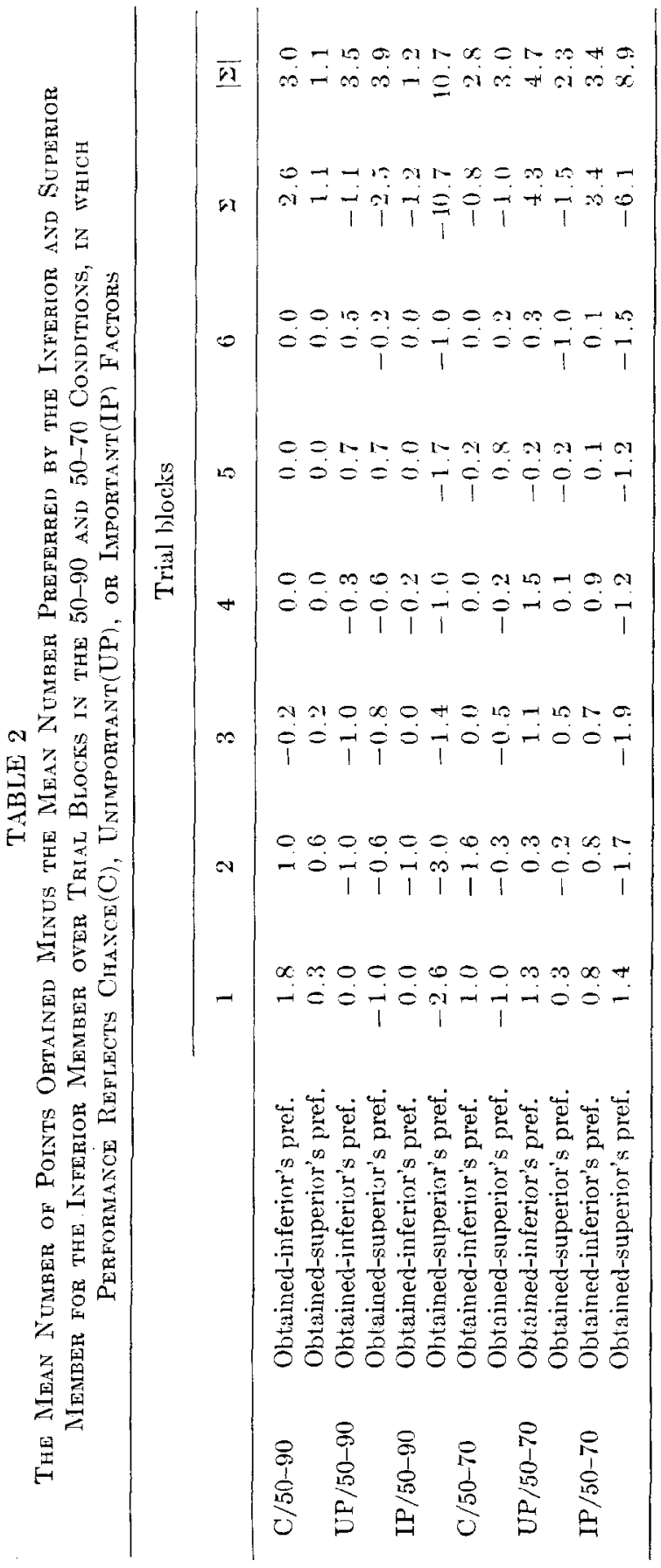


obtained $(F=4.39,2$ and $24 d f, p<.03)$. As the importance of the performance increases, the superior member prefers to assign more points to his inferior partner than the latter feels he should receive. No reliable effects appear for the Performance Difference $\times$ Performance Importance interaction.

\section{DISCUSSION}

To distribute a status such as task responsibility so as to maximize the expected value of its outcome, a group may be forced to violate common standards of equity and thereby to do considerable harm to affective relations among members. The circumstances under which this is likely to occur were specified as follows: If a rational assignment requires marked discrepancies in status, inequities occur (1) as the individual differences in task proficiency decrease and (2) as the status becomes an increasingly significant reward or cost. Inequities are said to have foreseeable interpersonal consequences, such as guilt or anger, which individuals prefer to avoid. Hence, if other means of maintaining equity are precluded, there should be greatest difficulty in achieving a rational distribution of responsibility when individual differences are small and the status conferred on the person is public recognition that he possesses or lacks a valuable trait. It is in these circumstances that the conflict between achieving an optimal assignment and avoiding inequity is most intense. ${ }^{2}$ Findings on the speed with which groups achieve such a distribution of responsibility support this analysis. Small differences in proficiency in an area of performance that had great importance to the person occasioned the greatest difficulty in redistributing responsibility, while large performance differences that had little significance to the individual occasioned the least. Since the subjects kept a running record of their own and their partner's successes and failures, it cannot he argued that the results reflect the increased difficulty in discriminating relative superiority as the difference between members decreased. Such an argument is also inconsistent with the rapid demotion of the inferior performer in the Chance condition even when individual differences were relatively small. Moreover, the rapid achievement of a rational redistribution in both Chance conditions precludes another rather powerful alternative interpretation, which is that the difficulty is due merely to

\footnotetext{
2In the present study there is no direct evidence as to whether or to what extent both members of the dyad experienced the emotional concomitants of inequity. This raises two issues that cannot here be resolved: (1) could the experimental effects have been produced by emotions that perhaps are irrelevant to the inequity, e.g., feelings of personal failure; and (2) could these effects have occurred if only one member was concerned with the inequity, or must this concern be shared.
} 
the subjects' lack of understanding of what assignment is necessary to maximize the expected value of their outcome.

Data on group decision time give further support to this argument. A tape recording was to be made of each discussion on the allocation of points. Due to experimenter and equipment malfunctioning, this was only obtaincd in about half of the groups in the IP and UP conditions. From these tapes it was determined which member initiated the discussion, whether his act was relevant to bargaining over points, and if so, whether it took the form of an offer ("Why don't I give you five of my chips?") or a demand ("You ought to give me five of your chips."). The length of time required to reach agreement about re-allocating points was also obtained. These partial data are presented in Table 3 for the first group discussion. Note that in the condition thought to pose the most difficulty in achieving a rational distribution (50-70/IP), the groups require the largest amount of time to reach a decision; in the condition thought to pose little difficulty (50-90/UP), the least time was required. It is striking that for the data available there is no overlap in decision times across conditions.

The present experimental setup attempted to preclude alternative means of maintaining equity other than by avoiding a rational distribution of responsibility. While the results suggest that we were at least in part successful, it would be unrealistic to assume complete success. It therefore might be worthwhile to consider what other means of maintaining equity existed that might not have been precluded by our procedure. There are a few sources of evidence to guide our conjectures. In Table 3 , for all but one of the taped groups, discussions are always initiated by

TABLE 3

Initiator, Type of Act Initiated, and Decision

Time during the First Discussion

\begin{tabular}{ccllc}
\hline Condition & Groups & $\begin{array}{c}\text { Initiating } \\
\text { performer }\end{array}$ & Act & $\begin{array}{c}\text { Group } \\
\text { decision-time } \\
\text { (secs.) }\end{array}$ \\
\hline $59-90$ & 1 & Inferior & Offer & 29 \\
IP & 2 & Inferior & Offer & 23 \\
$50-90$ & 1 & Inferior & Offer & 8 \\
UP & 2 & Inferior & Offer & 8 \\
$50-70$ & 3 & Inferior & Offer & 10 \\
IP & 1 & Inferior & Offer & 41 \\
$50-70$ & 2 & Inferior & Offer & 34 \\
UP & 1 & Superior & Delluand & 12 \\
& 2 & Inferior & Offer & 19 \\
\hline
\end{tabular}


the inferior performer who makes an offer to his partner. In Table 2, for those conditions with potentially the largest inequity, especially IP $/ 50$ 90, IP $/ 50-70$, and UP/50-70, the inferior performer more than his partner evidences a preference that approximates a rational distribution. Thus, he is more severe with himself than is his successful co-worker. Finally, if we take as a measure of relative influence in decision-making the absolute difference between a member's initial preference and that distribution agreed upon by the group, it is apparent from Table 2 that in those conditions in which a large incquity is in the offing, the inferior member exerts greater influence. Given these bits and pieces of data, what conjectures can be made about interpersonal tactics to minimize guilt or embarrassment on the part of the superior performer and anger or humiliation on the part of the inferior performer? It does not seem unreasonable to infer the following pattern from them. Recall that individual differences in performance were quite clear. Not only was each member's success or failure observed by his partner, but each kept a continuous record of these events. Everyone involved, including the experimenter to the extent that his opinion was relevant to the subjects, was no doubt recognized to possess perfect information on the performance of the two members. Hence, we ean assume that the less successful member recognized his own inferiority and with some justice felt that this inferiority was apparent to the others. While he would like to change this evaluation, it is soon obvious to him that his performance cannot be improved. There is, however, another area of activity-the decision to distribute responsibility-which is equally important in determining the value of the group outcome. If the inferior performer appears to understand what is required before his more successful partner does, he may be able to recoup respect and compensate himself for the humiliation of being divested of task responsibility. Were this strategem used in the present situation we would expect (and did observe) the inferior performer to initiate the decision-making discussion and to forcefully advocate a rational distribution of responsibility more frequently than the superior performer, especially when the difference in performance is relatively small or when the responsibility assigned to an individual is of particular significance to him. Admittedly, in advocating such a distribution, the inferior performer seals his fate, since there is little doubt that his partner will accede to his request and from that point his performance will count for little. At the same time, martyrdom has its social rewards. A rational distribution of responsibility might well be foreseen as inevitable, yet by initiating a policy which, when implemented, can only shame him, the inferior performer not only evidences the admirable trait of altruism, but at the same time displays an acute understanding of 
organizational problems. In short, through such tactics an inferior performer may gain compensatory benefits, that is, being recognized as the "causal locus" for selfless and intelligent, social planning.

The attempts to maintain or restore equity on the part of the less successful performer can complement rather nicely the tactics of his partner who laas a similar end in mind. Again, since the performance situation is quite unambiguous, the more successful member not only recognizes his partner's inferiority but, equally importantly, he may be rathcr ecrtain that his partncr is also aware that this recognition cxists. If the superior member further assumes that his partner wishes to obtain the most valuable outcome possible under the circumstances and that he understands how responsibility must be redistributed to achieve this result (these are not dangerous assumptions for they are readily tested during the discussion), he can, so to speak, "relax" and allow his partner to take the lead in arranging matters. Hence, he in part reduces the embarrassment of benefiting from an inequity by having the rictim initiate the process. Furthermore, research on choice behavior (Brehm and Cohen, 1962) suggests that by not compelling compliance but giving his partner the opportunity to initiate and control the decision to redistribute responsibility, the more successful member may increase the other's commitment to a status hierarchy that under other conditions would be considered eminently unfair.

These considerations of tactics to maintain or restore equity are, by and large, speculative. We make them not only on the grounds of reasonableness but also because they offer a consistent explanation of the data on individual distribution preferences and decisions to redistribute. Thus, when an inequity threatens, the superior member prefers a relatively lenient redistribution and his partner prefers one that is relatively severe. Furthermore, in those conditions in which a relatively large inequity threatens, the inferior member appears to exert greater influence than does his superior partner over the group decision. Finally, that the latter is rather relaxed about overtly demanding a rational assignment of responsibility is suggested by the incomplete data on discussions to redistribute, in which the bargaining is rarely initiated by superior members but almost always by the inferior member in the form of an offer to divest himself of points. It would probably be wise, as well as interesting, in future experiments on this problem, not to attempt to preclude tactics aimed at maintaining equity but to build them inlo the design is a variable. For instance, it follows from the above considerations that when compensatory actions that do not endanger the value of the group outcome are possible (for example, the inferior member may be given a larger share of the joint payoff, more affection, or greater "idiosyncrasy 
credit" than ordinarily would be the case), then a rational distribution of responsibility involving differences in status that are in no way commensurate with the differences in performance may be achieved with less difficulty.

\section{REFERENCES}

Adams, J. S. Inequity in social exchange. In L. Berkowitz (Ed.), Advances in experimental social psychology. New York: Academic Press, 1965. Pp. 267-299.

BreHM, J. W., ANd CoHeN, A. R. Explorations in cognitive dissonance. New York: Wiley, 1962.

Burnstein, E., AND Zasonc, R. B. Individual task performance in a changing social structure. Sociometry, 1965, 28, 16-29. (a)

Burnstein, E., and Zajonc, R. B. The effect of group success on the reduction of status incongruence in task-oriented groups. Sociometry, 1965, 28, 349-362. (b)

Homans, G. C. Social behavior: Its elementary forms. New York: Harcourt, 1961.

$\mathrm{Z}_{\mathrm{AJONC}}, \mathrm{R}$. B. The requirements and design of a standard group task. Journal of Experimental Social Psychology, 1965, 1, 71-88.

(Received September 28, 1967) 